\title{
ROLE OF DEXMEDETOMIDINE IN ANESTHESIA AND CRITICAL CARE
}

\author{
Baljit Singh Bajwa1, Satpal ${ }^{2}$
}

\section{HOW TO CITE THIS ARTICLE:}

Baljit Singh Bajwa, Satpal. "Role of Dexmedetomidine in Anesthesia and Critical Care". Journal of Evolution of Medical and Dental Sciences 2014; Vol. 3, Issue 43, September 11; Page: 10711-10721,

DOI: $10.14260 /$ jemds/2014/3396

ABSTRACT: The potential uses of dexmedetomidine (DEX), a highly selective $\alpha 2$ - adrenoceptor agonist are very diverse Although not orally active, DEX shows good bioavailability when administered via various other routes like intranasal, buccal, IM than intra-venous. DEX has similar pharmacokinetics in all age groups. Its side effects are predictable and easily treatable; hence it has found a place as a part of fast-tracking anesthesia regimens in children. DEX is the sedative of choice for peri-operative use in high- risk patients, since it is cardioprotective, neuroprotective and renoprotective. Premedication with DEX obtunds the autonomic pressor responses due to laryngoscopy and endotracheal intubation when used as an adjuvant to general anesthesia. DEX in high doses offers another approach to manage morbidly obese patients and patients with a compromised airway; without causing any cardiorespiratory depression. It is near ideal hypotensive agent used for controlled hypotension. Availability of an antidote (Atipamezole) with similar elimination half-life is taking the drug into new frontiers.The aim of this review is to present the most recent topics regarding the advantages in using dexmedetomidine in clinical anesthesia and in critical care, while discussing the controversial issues of its harmful effects.

KEYWORDS: Dexmedetomidine, intensive care unit sedation, 2-adrenergic receptor agonist.

INTRODUCTION: 2-adrenergic receptor (2-AR) agonists have been successfully used in several clinical settings in view of diverse actions which include sedation, analgesia, anxiolytic perioperative sympatholytic, cardiovascular stabilizing effects, reduced anesthetic requirements, and preservation of respiratory function. ${ }^{[1]}$

Dexmedetomidine is a relatively new drug approved at the end of 1999 by the Food and Drug Administration (FDA) for humans use for short-term sedation and analgesia $(<24$ hours) in the intensive care unit (ICU). Dexmedetomidine is a useful sedative agent with analgesic properties, hemodynamic stability and ability to recover respiratory function in mechanically ventilated patients facilitating early weaning.[2] Dexmedetomidine became alpha 2 agonist of choice, due to its greater alpha1 alpha 2 affinity (8 times greater than clonidine),[2,3] with alpha-2/alpha-1 binding affinity ratio of 1620:1.

This increase selectivity result in more predictable and effective sedation and analgesia and fewer side effect ${ }^{[4]}$ Dexmedetomidine has evolved as a panacea for various procedures with multiple promising delivery routes.[2-5] Besides being a new modality of sedation and analgesia in ICU patient management, ${ }^{[3]}$ it has been studied in several other perioperative settings, which will be discussed.

CHEMICAL STRUCTURE: Dexmedetomidine is the dextrorotatory S-enantiomer of medetomidine, an agent used in veterinary medicine. ${ }^{[4]}$ It is chemically.

(S)-4-[1-(2, 3-dimethylphenyl) ethyl]-3Himidazole. 


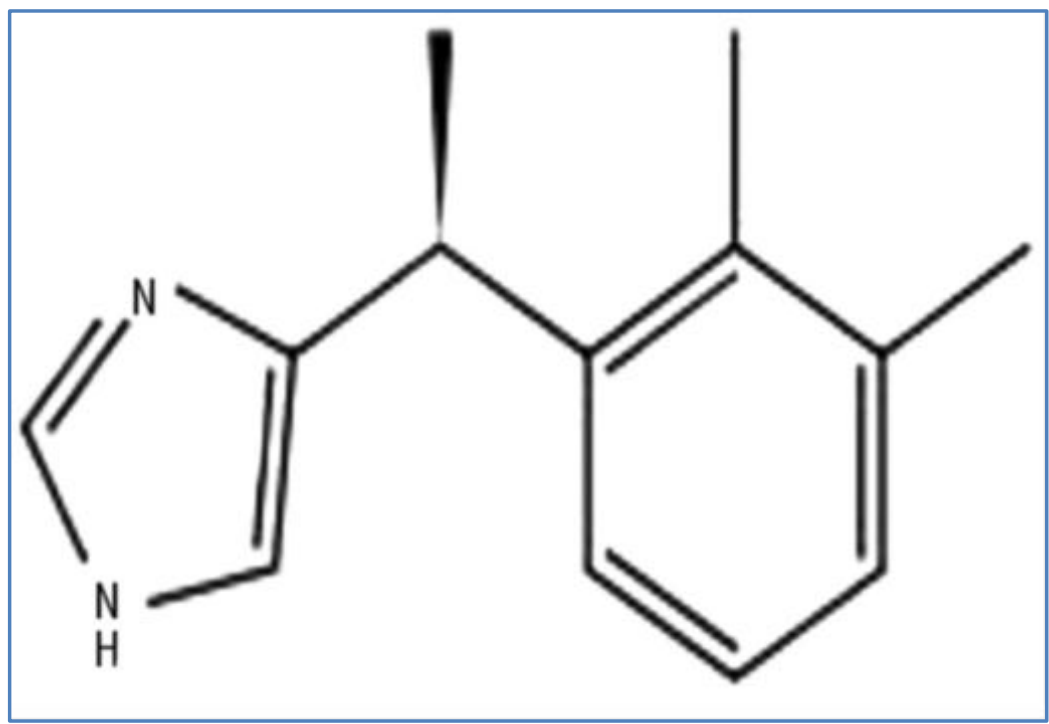

Fig. 1

MECHANISM OF ACTION: 2-AR agonists produce clinical effects after binding to G-Protein-coupled 2-AR, of which there are three subtypes (2A, 2B, and 2C) with each having different physiological functions and pharmacological activities. These receptor subtypes are found ubiquitously in the central, peripheral, and autonomic nervous systems, as well as in vital organs and blood vessels.[5] Dexmedetomidine is 8 to 10 times more selective towards 2-AR than clonidine.[6]

Neither clonidine nor dexmedetomidine is totally selective for any one of the 2-AR subtypes, but dexmedetomidine seems to have higher 2A-AR and 2C-AR affinity than clonidine.[7] Locus ceruleus of the brain stem is the principal site for the sedative action and spinal cord is the principal site for the analgesic action, both acting through 2A-AR. In the heart, the dominant action of 2-AR agonists is a decrease in tachycardia (through blocking cardioaccelerator nerve) and bradycardia via 2A-AR (through a vagomimetic action). In the peripheral vasculature, there is sympatholyticmediated vasodilatation and smooth muscle cells receptor-mediated vasoconstriction. ${ }^{[8]}$

The mechanism for the anti-shivering and diuretic actions has yet to be established firmly.[9]

Activation of postsynaptic $\alpha 2$ - adrenoceptors is responsible for peripheral actions of the drug.[10,11] Activation of a2 receptors leads to dose dependent reduction in the level of plasma catecholamines (maximum 89\%), bradycardia and hypotension secondary to sympathetic inhibition of medullary vasomotor center.[12,13] a2-adrenoceptors do not have an active role in the respiratory center, therefore, DEX throughout a broad range of plasma concentration (up to $8 \mathrm{ng} / \mathrm{ml}$ ), has minimal effects on the respiratory system.[12-14]

DEX does not have any direct effect on contractility of the myocardium. ${ }^{[5,16]}$ DEX evokes a biphasic blood pressure response: $\alpha-2 \mathrm{~B}$ adrenergic receptors are responsible for the initial short hypertensive phase while subsequent hypotension is mediated by $\alpha 2 \mathrm{~A}$ - adrenergic receptors. ${ }^{[9,15]}$ This direct effect on the peripheral vascular smooth muscle usually lasts for up to 10 min. ${ }^{[4,5]}$ It is observed that DEX does not alter the sweating threshold; there is a dose dependent decrease in the vasoconstriction. 


\section{REVIEW ARTICLE}

Pharmacokinetics/Pharmacodynamics: Although not orally active, DEX shows good bioavailability when administered via various other routes (than conventional intra-venous route) such as intranasal, intramuscular, buccal, sublingual, intragastric, regional, intra-articular.[15,17,18]

Pharmacokinetics of the active DEX molecule does not change with age, sex or in patients with renal failure.[5] In clinical doses, DEX also exhibits decongestant, antisialagogue, anti-shivering, antiemetic effects.[10-16]

Other claimed advantages include minimal respiratory depression with cardioprotection, neuroprotection and renoprotection, thus making it useful at various situations including offsite procedures. When DEX is infused with doses more than $1.5 \mathrm{~g} / \mathrm{kg}$, bradycardia and hypotension have been reported in almost $40 \%$ healthy surgical patients. ${ }^{[19]}$ Usually, these temporary effects are predictable and can be successfully treated with vagolytics, vasopressors and volume infusions.[20]

Metabolism and Excretion: Dexmedetomidine undergoes almost complete biotransformation through direct N-glucuronidation and cytochrome P-450 (CYP 2A6)-mediated aliphatic hydroxylation to inactive metabolites. Metabolites are excreted in the urine (about 95\%) and in the feces (4\%).[21] Dose adjustments are required in patients with hepatic failure because of the lower rate of metabolism.

\section{CLINICAL PHARMACOLOGY:}

Cardiovascular System: Dexmedetomidine evokes a biphasic blood pressure response: A short hypertensive phase and subsequent hypotension. ${ }^{[22]}$ The two phases are considered to be mediated by two different 2-AR subtypes: the $-2 \mathrm{~B} A \mathrm{~A}$ is responsible for the initial hypertensive phase, whereas hypotension is mediated by the 2A-AR. ${ }^{[23]}$

In younger patients with high levels of vagal tone, bradycardia and sinus arrest have been described which were effectively treated with anticholinergic agents (atropine, glycopyrrolate). In pt. receiving DEX. The reduction in rate pressure product and myocardial oxygen demand reduces subsequent myocardial ischemia and infarction. This is beneficial for cardiac patient.[13]

Dexmedetomidine in addition to blunting the hemodynamic response to endotracheal intubation also reduces the extent of myocardial ischemia during cardiac surgery. [58] Dexmedetomidine has been successfully used to manage patients with pulmonary hypertension undergoing mitral valve replacement, with reduction in pulmonary vascular resistance, pulmonary artery pressure, and pulmonary capillary wedge pressures.[5]

Central Nervous System: Dexmedetomidine reduces cerebral blood flow and cerebral metabolic requirement of oxygen but its effect on intracranial pressure (ICP) is not yet clear. Dexmedetomidine modulates spatial working memory, enhancing cognitive performance besides having sedative, analgesic, and anxiolytic action through the 2-AR.[24]

Studies suggest the likelihood of its neuroprotective action by reducing the levels of circulating and brain catecholamines and thus balancing the ratio between cerebral oxygen supplies, reducing excitotoxicity, and improving the perfusion in the ischemic penumbra. It reduces the levels of the glutamate responsible for cellular brain injury, especially in subarachnoid hemorrhage.[25]

It has been shown to limit the morphologic and functional effects after ischemic (focal and global) and traumatic injury to the nervous system. 
Respiratory Effects: Dexmedetomidine effect on respiration appears to be similar in order of magnitude to those seen in the heavy sleep state.[26] Dexmedetomidine does not suppress respiratory function, even at high doses.[27] It has no adverse effects on respiratory rate and gas exchange when used in spontaneously breathing ICU patients after surgery.[26]

It helps in maintaining sedation without cardiovascular instability or respiratory drive depression and hence may facilitate weaning and extubation in trauma/surgical ICU patients who have failed previous attempts at weaning because of agitation and hyperdynamic cardiopulmonary response. ${ }^{[2,28]}$ Dexmedetomidine in high dose offer another approach to managing the patient with obstructive sleep apnoea, in morbidly obese patients, without causing any cardio respiratory depression and ensuring neuromuscular recovery and smooth emergence. ${ }^{[27,28]}$

Endocrine and Renal Effects: Dexmedetomidine activates peripheral presynaptic 2- AR which reduces the release of catecholamines, and hence reduces sympathetic response to surgery.[29] sedation. ${ }^{[30]}$

ADVERSE EFFECTS: The various reported side effects are hypotension, hypertension, nausea, vomiting, dry mouth, bradycardia, atrial fibrillation, pyrexia, chills, pleural effusion, atelectasis, pulmonary edema, hyperglycemia, hypocalcaemia, acidosis, etc. Rapid administration of dexmedetomidine infusion (Loading dose of $1 \mathrm{mcg} / \mathrm{kg} / \mathrm{hr}$ if given in less than 10 minutes) may cause transient hypertension mediated by peripheral 2B- AR vasoconstriction.[5]

But hypotension and bradycardia may occur with ongoing therapy mediated by central 2A$A R$, causing decreased release of noradrenaline from the sympathetic nervous system. Long-term use of dexmedetomidine leads to super sensitization and up regulation of receptors; so, with abrupt discontinuation, a withdrawal syndrome of nervousness, agitation, headaches, and hypertensive crisis can occur.[31]

Dexmedetomidine is not recommended in patients with advanced heart block and ventricular dysfunction. [5] FDA has classified it as a category $C$ pregnancy risk, so the drug should be used with extreme caution in women who are pregnant.

\section{CLINICAL APPLICATIONS OF DEXMEDETOMIDINE:}

Premedication: Dexmedetomidine is used as an adjuvant for premedication, especially in patients susceptible to preoperative and perioperative stress because of its sedative, anxiolytic, analgesic, sympatholytic, and stable hemodynamic profile. Dexmedetomidine decreases oxygen consumption in the intraoperative period (up to 8\%) and in the postoperative period (up to 17\%).[32] Premedication dose is 0.33 to $0.67 \mathrm{mg} / \mathrm{kg}$ IV given 15 minutes before surgery (this dose minimizes side effects of hypotension and bradycardia).

Intraoperative Use: Dexmedetomidine attenuates hemodynamic stress response to intubation and extubation by sympatholysis. ${ }^{[26,33,35]}$ It is successfully used in intravenous dose varying from 0.25 to 1 $\mathrm{mcg} / \mathrm{kg}$ for attenuating intubation response. Dose in range of $0.5 \mathrm{mcg} / \mathrm{kg}$ not only blunted the extubation response but also reduced the emergence reaction and analgesic requirement to extubation following rihnoplasty and neurosurgery.[22] 
In view of absent respiratory depression, it can be continued at extubation period unlike other drugs. Dexmedetomidine potentiates anesthetic effect of all the anesthetic agents irrespective of the mode of administration (intravenous, inhalation, regional block). Intraoperative administration of dexmedetomidine in lower concentrations has reduced the requirement of other anesthetic agents; fewer interventions to treat tachycardia; and a reduction in the incidence of myocardial ischemia.[34]

However, side effects like bradycardia and hypotension are limitations to its use necessitating need for pharmacological rescue therapy. These effects may be attributed to the combined properties of volatile anesthetics such as vasodilatation and myocardial depression. Dexmedetomidine administered in high concentrations may cause systemic and pulmonary hypertension because of direct peripheral vascular effects or may compromise myocardial function and blood pressure.

Locoregional Analgesia: Highly lipophilic nature of dexmedetomidine allows rapid absorption into the cerebrospinal fluid and binding to 2-AR of spinal cord for its analgesic action. It prolongs the duration of both sensory and motor blockade induced by local anesthetics irrespective of the route of administration (e.g., epidural,[36] caudal,[37] or spinal.[38]).

Dose varying from 3 to $15 \mathrm{mcg} / \mathrm{kg}$ have been used as adjuvant to bupivacaine for spinal anesthesia. Dexmedetomidine though enhances both central and peripheral neural blockade by local anesthetics; [38] however, the peripheral neural blockade is due to its binding to 2A-AR. [39] Dexmedetomidine has been successfully used in intravenous regional anesthesia (IVRA),[40] brachial plexus block, ${ }^{[41]}$ and intraarticularly. ${ }^{[41,42]}$

Addition of $0.5 \mathrm{mg} / \mathrm{kg}$ dexmedetomidine to lidocaine for IVRA improves quality of anesthesia and improves intraoperative-postoperative analgesia without causing side effects.[40] Dexmedetomidine added to levobupivacaine for axillary brachial plexus block $(0.5 \mathrm{mcg} / \mathrm{kg})$ shortens the onset time and prolongs the duration of the block and postoperative analgesia.[41]

Intraarticular dexmedetomidine in patients undergoing arthroscopic knee surgery improves the quality and duration of postoperative analgesia.[41,42] Dexmedetomidine activates 2-AR in the spinal cord reducing transmission of nociceptive signals like substance P. It has significant opioidsparing effect and is useful in intractable neuropathic pain.[25]

Sedation in Intensive care Unit: Dexmedetomidine has become popular sedative agent in ICU because of its ability to produce cooperative sedation, and. patients remain awake, calm, and are able to communicate their needs. It does not interfere with the respiratory drive or produce any agitation, hence facilitating early weaning from the ventilator, thereby reducing overall ICU stay costs.[43]

The maintenance of natural sleep during sedation might speed recovery time in the ICU. Dexmedetomidine currently is approved by FDA for use in ICU for not more than 24 hours; though many studies have reported its safe use for longer duration. ${ }^{[4]}$ Dexmedetomidine when compared with conventional sedatives and opiates has been demonstrated to be associated with both sedative and analgesic sparing effect, reduces delirium and agitation, minimal respiratory depression and desirable cardiovascular effect. ${ }^{[45,46]}$

In ICU the loading dose of dexmedetomidine for adult pt. is 0.6 to $1 \mathrm{mcg} / \mathrm{kg} / \mathrm{hour}$ over $10 \mathrm{~min}$. then followed by maintenance dose of 0.2 to $0.7 \mathrm{mcg} / \mathrm{kg} / \mathrm{hour}$ can be given and maintenance dose is titrated until required level of sedation is reached. 


\section{REVIEW ARTICLE}

Dose up to $2.5 \mathrm{mcg} / \mathrm{kg} / \mathrm{hr}$ for up to 7 days, with no rebound effect on with drawl and no compromise in haemodynamic stability have been used in clinical trials.

Dexmedetomidine in Monitored Anesthesia Care (MAC): Dexmedetomidine is an attractive agent for shortterm procedural sedation and has been safely used in transe-sophageal echocardiography, ${ }^{[47]}$ colonoscopy, ${ }^{[48]}$ awake carotid endarterectomy, ${ }^{[49]}$ shockwave lithotripsy, ${ }^{[44]}$ vitreoretinal surgery,[50] elective awake fiberoptic intubation, ${ }^{[51]}$ pediatric patients undergoing tonsillectomy, ${ }^{[52]}$ and pediatric MRI.[53]

The usual dose of dexmedetomidine for procedural sedation is $1 \mathrm{mg} / \mathrm{kg}$, followed by an infusion of $0.2 \mathrm{mg} / \mathrm{kg} / \mathrm{h}$. Its onset of action is less than 5 minutes and the peak effect occur within 15 minutes. As the pharmacologic effects of dexmedetomidine can be reversed by the 2-AR antagonist atipamezole,[54] dexmedetomidine provides a titratable form of hypnotic sedation that can be readily reversed.

Controlled Hypotension: Dexmedetomidine is an effective and safe agent for controlled hypotension mediated by its central and peripheral sympatholytic action. Easy administration of dexmedetomidine, predictability with anesthetic agents, and lack of toxic side effect while maintaining adequate perfusion of the vital organs makes it a near-ideal hypotensive agent. Spinal fusion surgery for idiopathic scoliosis,[55] septoplasty and tympanoplasty operations,[56] and maxillofacial surgery ${ }^{[57]}$ have been safely done with dexmedetomidine-controlled hypotension.

Neurosurgery: Dexmedetomidine provides stable cerebral hemodynamics without sudden increase in ICP during intubation, extubation, and head pin insertion. It attenuates neurocognitive impairment (delirium and agitation) allowing immediate postoperative neurological evaluation.

It exerts its neuroprotective effects through several mechanisms which make the usage of this drug a promising tool during cerebral ischemia. ${ }^{[25]}$ It does not interfere with neurological monitors ${ }^{[5]}$ and has an upcoming role in "functional" neurosurgery. This includes awake craniotomy for the resection of tumors or epileptic foci in eloquent areas, and the implantation of deep brain stimulators for Parkinson's disease.[5]

Obesity: Dexmedetomidine does not cause respiratory depression and has been infused at a dose of $0.7 \mathrm{~g} / \mathrm{kg}$ intra operatively to avoid respiratory depression due to narcotic usage in a morbidly obese patient.[59]

Obstetrics: Dexmedetomidine has been successfully used as an adjunct to unsatisfactory analgesia by systemic opioids in laboring parturient who could not benefit from epidural analgesia.[60] It provides maternal hemodynamic stability, anxiolysis, and stimulation of uterine contractions. It is retained in placental tissue and passes less readily into the fetal circulation than clonidine because of high lipophilicity and thereby has less susceptibility to cause fetal bradycardia. In spinal anesthesia dose of $0.25 \mathrm{mcg} / \mathrm{kg}$ can be safely given to parturient patient.

Pediatrics: It is currently being used off-label as an adjunctive agent in pediatric patients for sedation and analgesia in the critical care unit and for sedation during noninvasive procedures in radiology like computed tomography and magnetic resonance imaging.[53] Addition of dexmedetomidine $2 \mathrm{mcg} / \mathrm{kg}$ to caudal bupivacaine 0.25 at $1 \mathrm{ml} / \mathrm{kg}$ significantly increases analgesia 


\section{REVIEW ARTICLE}

after recovery from anesthesia in children aged 6 months to 6 years without increasing incidence of side effect.[34]

Other Uses: The literature suggests other potential uses for dexmedetomidine, for example:

- Dexmedetomidine has been used successfully in the treatment of withdrawal from benzodiazepines, opioids, alcohol, and recreational drugs.

- As an adjunct in otorhinolaryngology anesthesia for middle ear surgery and rhinoplasty.

- As an adjunct in the repair of aortic aneurysms.

- Management of tetanus in ICU.

- As an anti-shivering agent.

- Dexmedetomidine is effective in preventing ethanol-induced neuro degeneration.

Precautions: Most of the adverse events associated with the use of DEX occur during or briefly y after loading of the drug. Multiple studies have demonstrated that by omitting or reducing the loading dose, adverse effects can be reduced.[12,19,20]

Although, avoiding the loading dose may prevent erratic hemodynamic effects, it may potentially prolong the onset of action and time to steady state for DEX. Sympatholytic or bradycardic actions of $\alpha 2$-adrenoceptor agonists may be deleterious in hypovolemic patients or patients with fixed stroke volume. Overdose of DEX may cause first-degree or second-degree atrioventricular block, atrial fibrillation. ${ }^{[13]}$

Severe bradycardia leading to cardiac arrest has been reported in the literature, but the case reports have multiple confounding factors that might have contributed to the cardiac arrest. Patients with hepatic dysfunction may require a lower dose of DEX than healthy subjects to achieve a similar response, given the extensive hepatic metabolism of DEX.[14]

As such, caution should be exercised when co-administering DEX with other sedatives, analgesics, vasodilators, or other negative chronotropic medications. ${ }^{[4]}$ DEX is not recommended for microvascular free flap procedures, as $\alpha 2$ agonists may cause direct vasoconstriction and reduction in flap blood flow.[14]

For the same reason, its use in neurovascular patients or those considered at high risk of vasospasm is not recommended. It is not indicated in recent acute epilepsy or uncontrolled seizure activity. The teratogenic effects of DEX have not been adequately studied at this time, but the drug does cross the placenta and should be used during pregnancy or breastfeeding only if the benefits justify the risk to the fetus.

CONCLUSION: Dexmedetomidine because of its unique properties offers its promising use in the wide spectrum of clinical setting and ICUs. It is a part of fast-tracking anesthesia regimens and offers anesthetic sparing and hemodynamic stabilizing effects.

As pharmacological effects of dexmedetomidine can be reversed by a 2-AR antagonist atipamezole, combination of dexmedetomidine and atipamezole can provide titratable form of sedation in the future. A large body of recent work in India supports its favorable profile in improving peri operative outcome in general and locoregional anesthesia.[24-30]

Few researchers have recommended it as best choice as primary sedative in adult and pediatric ICU, for short term as well as long term use.[2-8] The availability of low dose ampoule50 micro gm./ml can be step ahead towards affordability in developing countries like India. 


\section{REFERENCES:}

1. Kemp KM, Henderlight L, Neville M. Precedex: Is it the future of cooperative sedation? Nursing 2008; 38 Suppl Critical: 7-8.

2. Takrouri MS, Seraj MA, Channa AB, el-Dawlatly AA, Thallage A, Riad W, et al. Dexmedetomidine in intensive care unit: A study of hemodynamic changes. Middle East J Anesthesiol 2002; 16: 587-95.

3. Takrouri MS. New concepts in intensive care: Dexmedetomidine and immunonutrition. Middle East J Anesthesiol 2002; 16: 567-72.

4. Dexmedetomidine. Available from: http: //en.wikipedia.org/wiki/ Dexmedetomidine.

5. Afsani N. Clinical application of dexmedetomidine. S Afr J Anaesthesiol Analg 2010; 16: 50-6.

6. Wagner DS, Brummett CM. Dexmedetomidine: As safe as safe can be. Semin Anesth Perioper Med Pain 2006; 25: 77-83.

7. Fairbanks CA, Stone LS, Wilcox GL. Pharmacological profiles of alpha 2 adrenergic receptor agonists identified using genetically altered mice and isobolographic analysis. Pharmacol Ther 2009; 123: 224-38.

8. Macdonald E, Koblka BK, Scheinin M. Gene targeting-homing in on alpha 2-adrenoceptorsubtype function. Trends Pharmacol Sci 1997; 18: 211-9.

9. Kamibayashi T, Maze M. Clinical Uses of a2-Adrenergic Agonists. Anesthesiology 2000; 93: 1345-9.

10. Guo TZ, Buttermann AE, Jiang JY, Maze M. Dexmedetomidine injection into the locus ceruleus produces antinociception. Anesthesiology 1996; 84: 873-81.

11. Jaakola ML, Salonen M, Lehtinen R, Scheinin H. The analgesic action of dexmedetomidine - a novel $\alpha 2$-adrenoceptor agonist- in healthy volunteers. Pain 1991; 46: 281-5.

12. Ebert TJ, Hall JE, Barney JA, Uhrich TD, Colinco MD. The effects of increasing plasma concentrations of dexmedetomidine in humans. Anesthesiology 2000; 93: 382-94.

13. Shehabi Y, Botha JA, Ernest D, Freebairn RC, Reade M, Roberts BL, et al. Clinical application, the use of dexmedetomidine in intensive care sedation. Crit Care Shock 2010; 13: 40-50.

14. Bergese SD, Candiotti KA, Bokesch PM, Zura A, Wisemandle W, Bekker AY. AWAKE Study Group. A Phase IIIb, randomized, double-blind, placebo-controlled, multicenter study evaluating the safety and effi cacy of dexmedetomidine for sedation during awake fi beroptic intubation. Am J Ther 2010; 17: 586-95.

15. Housmans PR. Effects of dexmedetomidine on contractility, relaxation, and intracellular calcium transients of isolated ventricular myocardium. Anesthesiology 1990; 73: 919-22.

16. Talke P, Tayefeh F, Sessler DI, Jeffrey R, Noursalehi M, Richardson C. Dexmedetomidine does not alter the sweating threshold, but comparably and linearly decreases the vasoconstriction and shivering thresholds. Anesthesiology 1997; 87: 835-41.

17. Dyck JB, Maze M, Haack C, Vuorilehto L, Shafer SL. The pharmacokinetics and hemodynamic effects of intravenous and intramuscular dexmedetomidine hydrochloride in adult human volunteers. Anesthesiology 1993; 78: 813-20.

18. Gertler R, Brown HC, Mitchell DH, Silvius EN. Dexmedetomidine: A novel sedative-analgesic agent. Proc (Bayl Univ Med Cent) 2001; 14: 13-21.

19. Anttila M, Penttilä J, Helminen A, Vuorilehto L, Scheinin H. Bioavailability of dexmedetomidine after extravascular doses in healthy subjects. Br J Clin Pharmacol 2003; 56: 691-3. 


\section{REVIEW ARTICLE}

20. Philipp M, Brede M, Hein L. Physiological significance of alpha (2)-adrenergic receptor subtype diversity: One receptor is not enough. Am J Physiol Regul Integr Comp Physiol 2002; 283: R287-95.

21. Franowicz JS, Arnsten AF. The alpha-2a noradrenergic agonist, guanfacine, improves delayed response performance in young adult rhesus monkeys. Psychopharmacology (Berl) 1998; 136: 8-14.

22. Bekker A, Sturaitis MK. Dexmedetomidine for neurological surgery. Neurosurgery 2005; 57: 110.

23. Venn RM, Hell J, Grounds RM. Respiratory effects of dexmedetomidine in the surgical patient requiring intensive care. Crit Care 2000; 4: 302-8.

24. Hsu YW, Cortinez LI, Robertson KM, Keifer JC, Sum-Ping ST, Moretti EW, et al. Dexmedetomidine pharmacodynamics: Part I: Cross-over comparison of the respiratory effects of dexmedetomidine and remifentanil in healthy volunteers. Anesthesiology 2004; 101: 1066-76.

25. Siobal MS, Kallet RH, Kivett VA, Tang JF. Use of dexmedetomidine to facilitate extubation in surgical intensive-care-unit patients who failed previous weaning attempts following prolonged mechanical ventilation: A pilot study. Respir Care 2006; 51: 492-6.

26. Ebert TJ, Hall JE, Barney JA, Uhrich TD, Colinco MD. The effects of increasing plasma concentrations of dexmedetomidine in humans. Anesthesiology 2000; 93: 382-94.

27. Venn R, Bryant A, Hall GM, Grounds RM. Effects of dexmedetomidine on adrenocortical function and the cardiovascular, endocrine and inflammatory responses in post-operative patients needing sedation in the intensive care unit. Br J Anaesth 2001; 86: 650-6.

28. Morgan GE, Mikhail MS, Murray MJ. Preoperative Medication in Clinical Anaethesia. In: Morgan GE, Mikhail MS, Murray MJ, Editors. 4th ed. New York: Mc graw Hill; 2006. p. 248.

29. Taittonen MT, Kirvela OA, Aantaa R, Kanto JH. Effect of clonidine and dexmedetomidine premedication on perioperative oxygen consumption and haemodynamic state. $\mathrm{Br} \mathrm{J}$ Anaesth 1997; 78: 400-6.

30. Scheinin B, Lindgren L, Randell T, Scheinin H, Scheinin M. Dexmedetomidine attenuates sympathoadrenal responses to tracheal intubation and reduces the need for thiopentone and peroperative fentanyl. Br J Anaesth 1992; 68: 126-31.

31. Aho M, Lehtinen AM, Erkola 0, Kallio A, Korttila K. The effect of intravenously administered dexmedetomidine on perioperative hemodynamics isoflurane requirements in patients undergoing abdominal hysterectomy. Anesthesiology 1991; 74: 997-1002.

32. Guler G, Akin A, Tosun E, Eskitafloglu E, Mizrak A, Boyaci A. Single-dose dexmedetomidine attenuates airway and circulatory reflexes during extubation. Acta Anaesthesiol Scand 2005; 49: 1088-91.

33. Schnaider TB, Vieira AM, Brandao AC, Lobo MV. Intraoperative analgesic effect of epidural ketamine, clonidine or dexmedetomidine for upper abdominal surgery. Rev Bras Anestesiol 2005; 55: 525-31.

34. El-Hennawy AM, Abd-Elwahab AM, Abd-Elmaksoud AM, El-Ozairy HS, Boulis SR. Addition of clonidine or dexmedetomidine to bupivacaine prolongs caudal analgesia in children. Br J Anaesth 2009; 103: 268-74. 
35. Kanazi GE, Aouad MT, Jabbour-Khoury SI, Al Jazzar MD, Alameddine MM, Al-Yaman R, et al. Effect of low-dose dexmedetomidine or clonidine on the characteristics of bupivacaine spinal block. Acta Anaesthesiol Scand 2006; 50: 222-7.

36. Yoshitomi T, Kohjitani A, Maeda S, Higuchi H, Shimada M, Miyawaki T. Dexmedetomidine enhances the local anesthetic action of lidocaine via an alpha-2A adrenoceptor. Anesth Analg 2008; 107: 96-101.

37. Memiş D, Turan A, Karamanlıg lu B, Pamukçu Z, Kurt I. Adding Dexmedetomidine to Lidocaine for Intravenous Regional Anesthesia. Anesth Analg 2004; 98: 835-40.

38. Esmaoglu A, Yegenoglu F, Akin A, Turk CY. Dexmedetomidine added to levobupivacaine prolongs axillary brachial plexus block. Anesth Analg 2010; 111: 1548-51.

39. Al-Metwalli RR, Mowafi HA, Ismail SA, Siddiqui AK, Al-Ghamdi AM, Shafi MA, et al. Effect of intra-articular dexmedetomidine on postoperative analgesia after arthroscopic knee surgery. $\mathrm{Br}$ J Anaesth 2008; 101: 395-9.

40. Paul S, Bhattacharjee DP, Ghosh S, Dawn S, Chatterjee N. Efficacy of intraarticular dexmedetomidine for postoperative analgesia in arthroscopic knee surgery. Ceylon Med J 2010; 55: 111-5.

41. Short J. Use of Dexmedetomidine for Primary Sedation in a General Intensive Care Unit. Crit Care Nurse 2010; 30: 29-38.

42. Kaygusuz K, Gokce G, Gursoy S, Ayan S, Mimaroglu C, Gultekin Y. A comparison of sedation with dexmedetomidine or propofol during shockwave lithotripsy: A randomized controlled trial. Anesth Analg 2008; 106: 114-9.

43. Shehabi Y, Botha JA, Ernest D, Freebairn RC, Reade M, Roberts BL, et al. Clinical application, the use of dexmedetomidine in intensive care sedation. Crit Care Shock 2010; 13: 40-50.

44. Pandharipande PP, Pun BT, Herr DL, Maze M, Girard TD, miller RR, et al. Effect of sedation with dexmedetomidine vs lorazepam on acute brain dysfunction in mechanically ventilated patients: The MENDS randomized controlled trial. JAMA 2007; 298: 2644-53.

45. Cooper L, Candiotti K, Gallagher C, Grenier E, Arheart KL, Barron ME. A Randomized, Controlled Trial on Dexmedetomidine for Providing Adequate Sedation and Hemodynamic Control for Awake, Diagnostic Transesophagea Echocardiography. J Cardiothorac Vasc Anesth 2011; 25: 233-7.

46. Jalowiecki P, Rudner R, Gonciarz M, Kawecki P, Petelenz M, Dziurdzik P. Sole use of dexmedetomidine has limited utility for conscious sedation during outpatient colonoscopy. Anesthesiology 2005; 103: 269-73.

47. Bekker AY, Basile J, Gold M, Riles T, Adelman M, Cuff G, et al. Dexmedetomidine for awake carotid endarterectomy: Efficacy, hemodynamic profile, and side effects. J Neurosurg Anesthesiol 2004; 16: 126-35.

48. Ghali A, Mahfouz AK, Ihanamäki T, El Btarny AM. Dexmedetomidine versus propofol for sedation in patients undergoing vitreoretinal surgery under sub-Tenon's anesthesia. Saudi J Anaesth 2011; 5: 36-41.

49. Bergese SD, Khabiri B, Roberts WD, Howie MB, McSweeney TD, Gerhardt MA, et al. Dexmedetomidine for conscious sedation in difficult awake fiberoptic intubation cases. J Clin Anesth 2007; 19: 141-4. 
50. Olutoye OA, Glover CD, Diefenderfer JW, McGilberry M, Wyatt MM, Larrier DR, et al. The effect of intraoperative dexmedetomidine on postoperative analgesia and sedation in pediatric patients undergoing tonsillectomy and adenoidectomy. Anesth Analg 2010; 111: 490-5.

51. Phan H, Nahata MC. Clinical uses of dexmedetomidine in pediatric patients. Paediatr Drugs 2008; 10: 49-69.

52. Aho M, Erkola O, Kallio A, Scheinin H, Korttila K. Comparison of dexmedetomidine and midazolam sedation and antagonism of dexmedetomidine with atipamezole. J Clin Anesth 1993; 5: 194-203.

53. El-Gohary MM, Arafa AS. Dexmedetomidine as a hypotensive agent: Efficacy and hemodynamic response during spinal surgery for idiopathic scoliosis in adolescents. Egyp J Anaesth 2010; 26: 305-11.

54. Ayoglu H, Yapakci O, Ugur MB, Uzun L, Altunkaya H, Ozer Y, et al. Effectiveness of dexmedetomidine in reducing bleeding during septoplasty and tympanoplasty operations. J Clin Anesth 2008; 20: 437-41.

55. Richa F, Yazigi A, El Hage C, Jebara S, Hokayem N, Antakly MC. Dexmedetomidine: An agent for controlled hypotension in maxilla-facial surgery. Eur J Anaesthesiol 2004; 21: 902-6.

56. Wijeysundera DN, Naik JS, Beattie WS. Alpha-2 adrenergic agonists to prevent perioperative cardiovascular complications: A meta analysis. Am J Med 2003; 114: 742-52.

57. Hofer RE, Sprung J, Sarr MG, Wedel DJ. Anesthesia for a patient with morbid obesity using dexmedetomidine without narcotics. Can J Anesth 2005; 52: 176-80.

58. Abu-Halaweh SA, Al Oweidi AK, Abu-Malooh H, Zabalawi M, Alkazaleh F, Abu-Ali H, et al. Intravenous dexmedetomidine infusion for labour analgesia in patient with preeclampsia. Eur J Anaesthesiol 2009; 26: 86-7.

59. Flacke JW, alpha 2-adrenergic agonist in cardiovascular anesthesia. J Cardiothoracic Vasc Anesthesia 1992; 6.344-59.

60. Chrtsotomou C, Schmitt CG. Dexmedetomidine; sedation, analgesia and beyond. Expert opin Drug Metabolism Toxicol 2008; 4, 619-27.

\section{AUTHORS:}

1. Baljit Singh Bajwa

2. Satpal

\section{PARTICULARS OF CONTRIBUTORS:}

1. Assistant Professor, Department of Anaesthesia and Critical Care. Punjab Institute of Medical Sciences (PIMS), Garah Road, Jalandhar.

2. Assistant Professor, Department of Anaesthesia and Critical Care. Punjab Institute of Medical Sciences (PIMS), Garah Road, Jalandhar.

\section{NAME ADDRESS EMAIL ID OF THE CORRESPONDING AUTHOR:}

Dr. Baljit Singh Bajwa, \#71/72, Tower Enclave, Phase 3, Near A. S. Farm, Post Office Tower Town, Jalandhar City.

Email: baljitbajwa7@gmail.com

$$
\begin{aligned}
& \text { Date of Submission: 13/08/2014. } \\
& \text { Date of Peer Review: 14/08/2014. } \\
& \text { Date of Acceptance: 05/09/2014. } \\
& \text { Date of Publishing: 10/09/2014. }
\end{aligned}
$$

